\title{
CC COBENGE \\ RELATO DE EXPERIÊNCIA DA DISCIPLINA DE CÁLCULO NUMÉRICO E APLICAÇÕES NO ENSINO REMOTO EMERGENCIAL DA UFPEL
}

\author{
DOI: $10.37702 / 2175-957 X . C O B E N G E .2021 .3440$
}

EDUARDO DA SILVA SCHNEIDER - schneider.ufpel@gmail.com

Universidade Federal de Pelotas

Rua Felix da Cunha 4048

96010-000 - PELOTAS - RS

Resumo: Neste trabalho, apresentamos um relato de experiência de como foi organizada e estruturada a disciplina de Cálculo Numérico e Aplicações para uma pequena turma de alunos do Centro de Engenharias da Universidade Federal de Pelotas no contexto da pandemia de COVID-19 sob uma perspectiva de ensino remoto emergencial no ano de 2020. Apresentamos as principais ferramentas exploradas dentro do ambiente virtual de aprendizagem e como essas foram utilizadas nos processos de ensino-aprendizagem, avaliação e registro de frequência. Além disso, apresentamos os resultados e algumas análises de uma pesquisa conduzida junto aos alunos matriculados na disciplina, com o intuito conhecer o perfil desses estudantes e, dessa forma, poder antecipar dificuldades e/ou explorar potencialidades do ensino remoto emergencial.

Palavras-chave: Cálculo numérico, ensino remoto emergencial, ambiente virtual de aprendizagem. 


\section{(c) COBENGE \\ RELATO DE EXPERIÊNCIA DA DISCIPLINA DE CÁLCULO NUMÉRICO E APLICAÇÕES NO ENSINO REMOTO EMERGENCIAL DA UFPEL}

\section{INTRODUÇÃO}

A COVID-19 (Coronavirus Disease 2019), é uma doença infeciosa causada pelo coronavírus da síndrome respiratória grave 2 (SARS-CoV-2). A doença foi observada pela primeira vez em dezembro de 2019 em moradores da cidade de Wuhan, na República Popular da China. Em 7 de janeiro de 2020, o agente causador foi identificado pelo Centro Chinês para Controle e Prevenção de Doenças (Chinese Centre for Disease Control and Prevention) (SOHRABI et al, 2020). A partir daí, o SARS-CoV-2 se disseminou para outras partes do mundo.

No Brasil, a pandemia de COVID-19 iniciou em 26 de fevereiro de 2020, com a confirmação do primeiro caso de um homem que testou positivo para a SARS-Cov-2 no estado de São Paulo. Em 17 de março de 2020, ocorreu o primeiro óbito por COVID-19 no país. A transmissão comunitária da COVID-19 em território nacional foi reconhecida em 20 de março de 2020 (OLIVEIRA et al, 2020).

Em Pelotas, a Universidade Federal de Pelotas (UFPel) preparava-se para iniciar o semestre letivo 2020/01, que teve seu início no dia 9 de março de 2020. No dia 13 de março de 2020, foi emitida uma portaria autorizando a realização de atividades administrativas da Universidade por meio de trabalho remoto (UFPel, 2020a). No dia 16 de março de 2020, foram suspensas as atividades acadêmicas e o calendário acadêmico de 2020 da UFPel (UFPel, 2020b). Nos meses subsequentes a Universidade se organizou de tal forma a ser possível que o trabalho docente também pudesse ser realizado, uma vez que o semestre letivo regular estava suspenso. Como fruto dos esforços de vários setores, foi proposta à comunidade acadêmica um "Calendário Alternativo" em que os estudantes e professores da instituição poderiam cursar e ministrar disciplinas, respectivamente, por adesão, no formato de ensino remoto emergencial (UFPel, 2020c, 2020d).

No contexto da pandemia de COVID-19 e da possibilidade de oferta de disciplinas no Calendário Alternativo, foi planejada, desenvolvida e implementada a disciplina de Cálculo Numérico e Aplicações para os estudantes do Centro de Engenharias (CEng) da UFPel sob uma perspectiva do ensino remoto emergencial.

Nas subseções 1.1 e 1.2, explicitamos alguns aspectos e definições do que vem a ser o Calendário Alternativo utilizado pela UFPel e o ensino remoto emergencial adotado.

\subsection{O Calendário Alternativo da UFPel}

De acordo com o Parecer Normativo No 12, de 28 de maio de 2020 da UFPel (UFPel, 2020d), foram estabelecidas as diretrizes para implementação do Calendário Alternativo (CA) na instituição. Como motivador para adoção do CA, foi sugerida a utilização de atividades remotas emergenciais de forma a manter a Universidade ativa e engajada no que se referia ao ensino de graduação e pós-graduação, mantendo professores e alunos em interação social, cognitiva e emocional e de forma a se apropriarem de outras metodologias pedagógicas, com o uso de ferramentas virtuais e de ensino remoto.

Como pontos que merecem destaque, o Parecer Normativo $\mathrm{N}^{\circ} 12$ determinava que:

- o CA ocorreria em 12 semanas letivas iniciando em 22 de junho de 2020;

- o CA trataria de ofertas de atividades acadêmicas possíveis de serem realizadas de forma remota emergencial; 
- a oferta de componentes curriculares seria analisada pelos colegiados de curso e departamentos tendo como critério essencial as condições (conhecimento) de os professores realizarem atividades acadêmicas utilizando as ferramentas online;

- não se exigiria um número mínimo de alunos por turma.

\subsection{Ensino Remoto Emergencial}

$\mathrm{Na}$ educação a distância (EaD), existe todo um planejamento, recursos e equipe multidisciplinar especializada, preparados para oferecer uma variedade de conteúdos e atividades em diferentes tipos de mídias digitais em plataformas educacionais on-line (HODGES et al, 2020). Um exemplo clássico de conteúdo pedagógico em EaD são as videoaulas, gravadas e disponibilizadas on-line, que não se resumem a gravação de uma aula que está acontecendo ao vivo, mas contam com todo um planejamento que permitem sua utilização por um longo período de tempo. É comum que as videoaulas sejam altamente roteirizadas e editadas, podendo até contar com a performance de atores na sua gravação.

$O$ ensino remoto emergencial (ERE) se assemelha ao EaD no que se refere a uma educação mediada pela tecnologia, mantendo os mesmos princípios da educação presencial (BREDARIOLI, 2020). Mas, diferente do EaD, o ensino remoto emergencial (ERE) tem pretensões um pouco mais modestas, oferecendo de forma temporária conteúdos e materiais comumente trabalhados de forma presencial e, agora, adaptados para a nova realidade do ensino remoto (HODGES et al, 2020)(RONDINI et al, 2020). Para exemplificar essa diferença, as videoaulas como concebidas para o EaD foram substituídas pelas gravadas ao vivo pelo próprio professor, simulando uma aula presencial que agora é distribuída de forma on-line dentro da plataforma de ensino, não necessariamente, tendo um roteiro ou edição realizados por profissionais com conhecimento técnico para tal. Outro exemplo é a adoção da curadoria digital de conteúdos e materiais utilizados em EaD que estão disponíveis de forma livre na rede, o que permite uma diversificação dos recursos disponíveis para os estudantes sem a necessidade de planejar, desenvolver e produzir tais recursos próprios para o ensino remoto ou ultimamente para o EaD.

Em virtude da pandemia de COVID-19, o ERE surge como uma das principais alternativas ao ensino presencial e EaD clássicos e passou ou ainda passa a ser adotado por muitas instituições de ensino no Brasil e no mundo nos diversos níveis de educação, seja ela básica ou superior (RONDINI et al, 2020).

\section{ORGANIZAÇÃO E ESTRUTURA DA DISCIPLINA}

A disciplina de Cálculo Numérico e Aplicações é uma disciplina comum a sete dos dez cursos de graduação do CEng da UFPel. A saber, os cursos que possuem essa disciplina nos seus currículos são: Engenharia Agrícola, Engenharia Geológica, Engenharia Civil, Engenharia de Petróleo, Engenharia de Produção, Engenharia de Controle e Automação e Engenharia Eletrônica. Em geral, a disciplina utiliza como metodologia de ensino aulas expositivo-dialogadas com uso de recursos computacionais tais como planilhas eletrônicas, softwares matemáticos ou alguma linguagem de programação para realizar os cálculos envolvendo números.

Para fazer a transição do ensino presencial para o ERE, uma das constantes preocupações nas fases de planejamento, desenvolvimento e implementação na disciplina de Cálculo Numérico e Aplicações foi assumir que os estudantes estavam entrando em contato o ERE pela primeira vez provavelmente. Sendo assim, seria preciso um esforço para ensinar, como os estudantes poderiam navegar pela disciplina para terem acesso, de 
forma satisfatória, a todas as informações, recursos e atividades disponíveis, além de ensinar os conteúdos próprios da disciplina.

A disciplina foi implementada no servidor e-AULA da UFPel, utilizando como ambiente virtual de aprendizagem (AVA) a plataforma Moodle. No AVA, estavam disponíveis, basicamente, três tipos de conteúdos: informações sobre a disciplina e como acessar e utilizar os recursos e atividades da disciplina, além dos recursos e atividades propriamente ditas. Aqui vale ressaltar que estamos utilizando as definições do Moodle (MOODLE, 2021) para recursos e atividades, ou seja,

- recursos são itens que o professor pode usar para promover o aprendizado, tais como livros, arquivos, pastas, páginas, etc;

- atividade, em geral, são algo em que cada estudante poderá interagir com outros estudantes e/ou o professor, por exemplo, questionários e fóruns de discussão.

No esforço de aproximar os estudantes à nova metodologia de ensino adotada ${ }_{2}$ foi disponibilizada toda uma seção da disciplina no AVA dedicada ao acolhimento e transição para o ERE. Essa seção continha informações claras e de fácil acesso para consulta, uma vez que os estudantes, por assim dizer, já estavam acostumados a "navegar" pelos semestres letivos na perspectiva de um ensino presencial, mas que agora poderia ser um pouco diferente sob a perspectiva de ERE. É importante destacar o papel de tal seção uma vez que nela estavam descritas (1) as principais informações sobre o funcionamento da disciplina: identificação da equipe de trabalho, metodologia de ensino, cronograma de atividades, bibliografia utilizada, horários de atendimento síncrono com o professor e monitoria, método de aferição da frequência e método de avaliação; e (2) recursos, internos ou externos ao AVA, e atividades para acolhimento dos estudantes e para exploração do próprio ambiente de aprendizagem. Na Figura 1, temos uma tela da seção de Informações Essenciais e de Apoio.

Figura 1 - Seção de Informações Essenciais e de Apoio

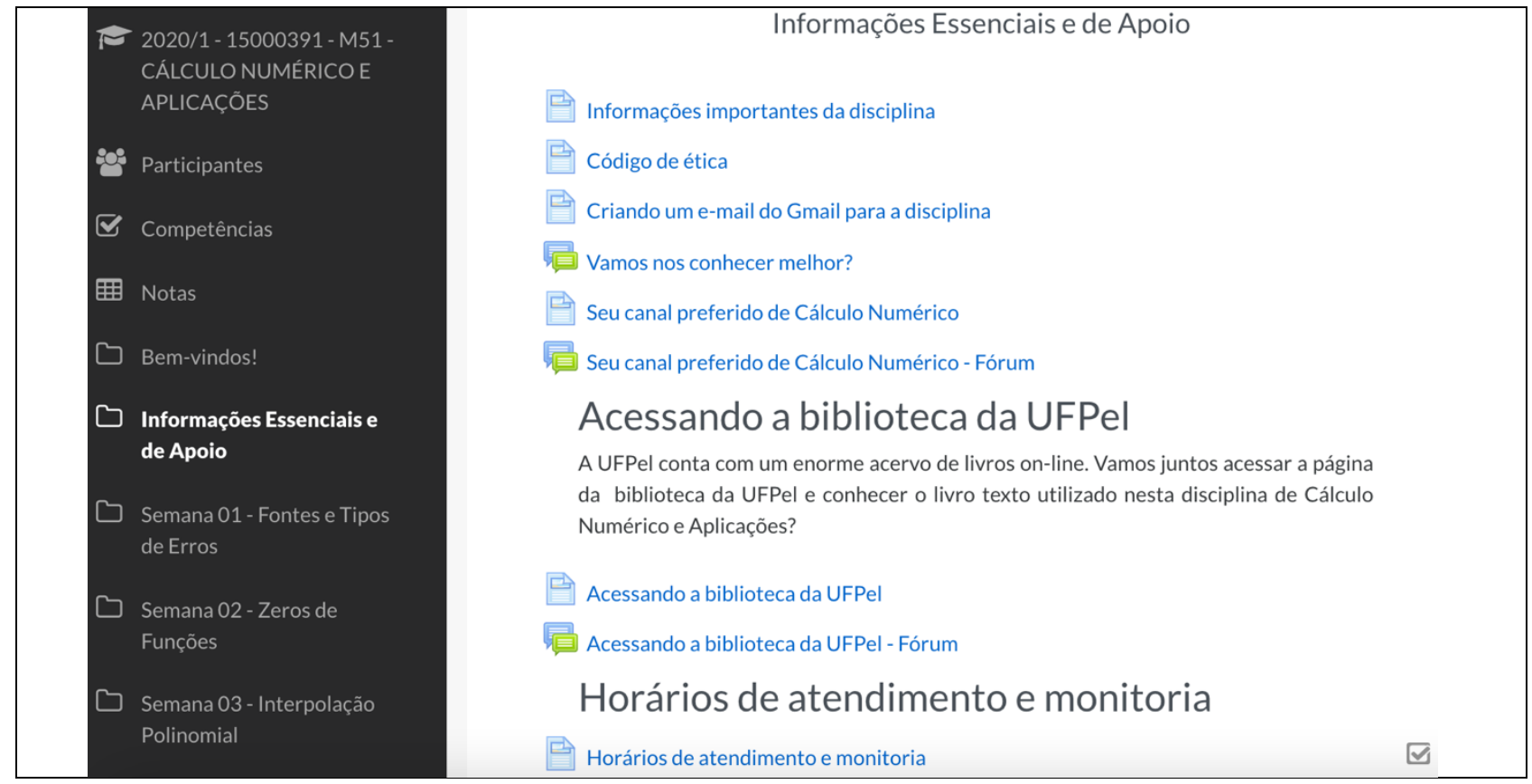

Fonte: tela do AVA da disciplina de Cálculo Numérico e Aplicações - Semestre Alternativo 2020. 


\subsection{Avaliação e registro de frequência}

Traçando um paralelo com o ensino presencial no que tangencia a avaliação, nesse os estudantes estavam acostumados a realizar 1 ou 2 provas ou trabalhos ao longo do semestre, sendo essas as atividades avaliadas para efeitos de aprovação ou reprovação na disciplina. No ERE adotamos um modelo de avaliação continuada com base em quizzes e fóruns de exercícios que eram avaliados semanalmente. Os quizzes consistiam em pequenos questionários desenvolvidos para aferir o entendimento dos materiais estudados de forma pontual, eram atividades propostas logo após uma leitura orientada do livro ou um pequeno vídeo sobre um conteúdo específico. Os fóruns de exercícios tinham o objetivo que os estudantes continuassem engajados na disciplina, compartilhando suas soluções dos exercícios recomendados com os demais colegas e professor, e possibilitava avaliar o entendimento e aplicabilidade dos conteúdos estudados de forma mais ampla. Adicionalmente, foram realizados mais dois trabalhos aplicados onde a temática escolhida relacionava os conteúdos da disciplina com modelagem matemática para a COVID-19. Os dados utilizados nos trabalhos consistiam em dados reais vindos do site do Ministério da Saúde do Brasil e permitiam verificar a aplicabilidade dos métodos numéricos estudados.

Da mesma forma que a avaliação sofreu alterações com a passagem do ensino presencial para o ERE, a aferição de frequência teria de ser feita de forma diferente dada as particularidades do ERE. A grande dificuldade era fazer uma transposição direta de com a frequência é medida e registrada no ensino presencial, onde tempo e espaço são determinados, por assim dizer, pela localização física da sala de aula e pelo momento em que o professor se encontra em sala de aula. Mesmo a disciplina contando com um momento síncrono semanal, uma webconferências para discussão dos conteúdos e dúvidas, adotamos um registro de frequência baseado nas atividades avaliadas realizadas semanalmente: para o aluno ter a frequência da semana ele precisava realizar todos os quizzes daquela semana bem como fazer uma postagem no fórum de exercícios com a resolução de um exercício previamente a ele designado. Não era mandatório a presença nas webconferências semanais para que os alunos pudessem ter a frequência registrada. Dessa forma, foi flexibilizada a participação dos estudantes nos momentos síncronos, uma vez que não se podia garantir todos os requisitos técnicos para os alunos estarem on-line nas webconferências, por exemplo, poderia haver instabilidades na internet ou até mesmo do servidor e-AULA.

\subsection{Acolhimento e adaptação aos recursos e atividades do AVA}

O acolhimento ou boas-vindas ao ambiente da disciplina foi pensado de forma a convidar os alunos a refletir sobre as particularidades do momento único que estávamos vivendo em função da pandemia de COVID-19 e da adoção do ERE e como isso iria impactar na forma de desenvolver a disciplina: conteúdos, materiais didáticos e interações entre os estudantes e desses com o professor. Também, nesse primeiro momento, os estudantes teriam, provavelmente, o primeiro contato com alguns recursos e atividades do AVA, principalmente aqueles que seriam utilizadas de forma constante desde a primeira semana até a última semana da disciplina.

Uma das atividades de acolhimento foi realizada através de um fórum de discussões. $\mathrm{Na}$ Figura 2, temos uma tela do fórum onde os estudantes da disciplina podiam se apresentar para os demais colegas. A intencionalidade pedagógica dessa atividade, além de tentar diminuir a distância física imposta pelo isolamento social, remetia a uma primeira tentativa de responder um fórum dentro do AVA. Como podemos notar na Figura 2, a primeira parte de instruções começava com uma saudação e então indicava as diretrizes ou um guia de como os estudantes poderiam elaborar suas apresentações pessoais; na segunda parte, havia uma instrução clara de como postar uma mensagem no fórum: "Para 
isso, é só clicar abaixo em Responder." Embora pareça simples postar uma resposta em um fórum de discussão, essa atividade permitiu que os estudantes pudessem "treinar" como fazer postagens em uma atividade não avaliada, sem o receio de estarem postando uma "resposta errada" ou de serem penalizados por não saberem fazerem postagens no AVA.

Figura 2 - Fórum: Vamos nos conhecer melhor?

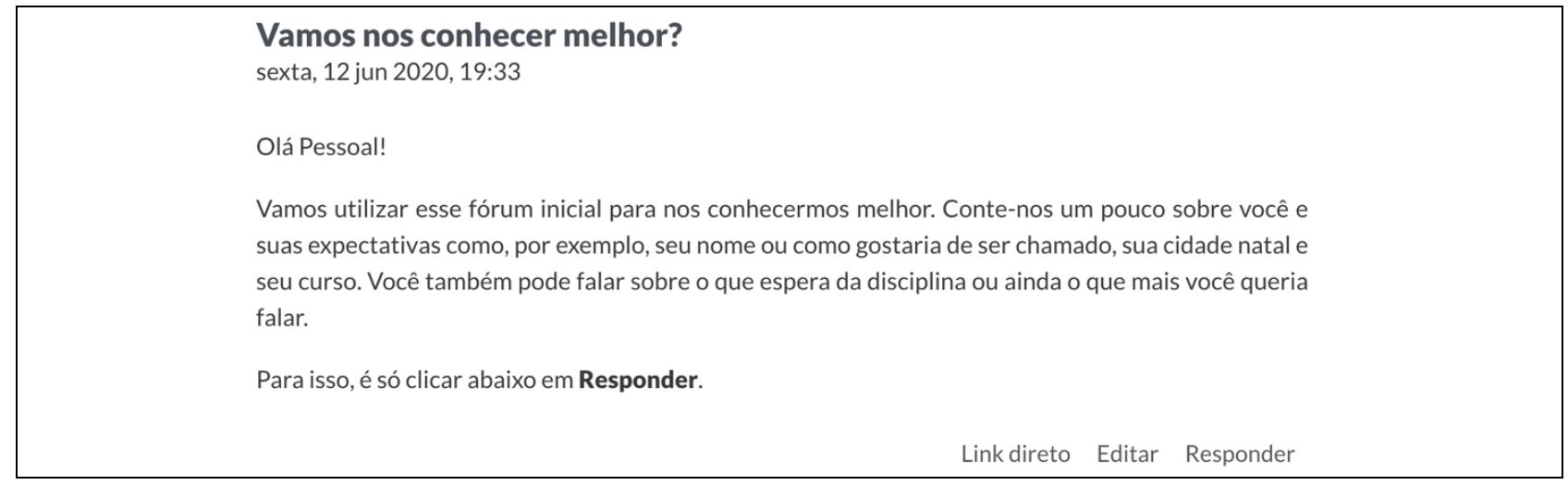

Fonte: tela do AVA da disciplina de Cálculo Numérico e

Aplicações - Semestre Alternativo 2020.

\subsection{Principais recursos utilizados}

A plataforma Moodle possui uma variedade de recursos que podem ser utilizados para disponibilizar itens (materiais didáticos), em diversos tipos de mídias, de forma a promover o aprendizado dos alunos. Na disciplina de Cálculo Numérico e Aplicação, os recursos página e arquivo foram os mais utilizados.

Como estratégia pedagógica foram adotados, predominantemente, três tipos de materiais didáticos na disciplina:

- textos produzidos pelo professor: em geral, disponibilizados através de um arquivo .PDF, tais textos versavam sobre tópicos não contemplados no livro texto da disciplina;

- leituras orientadas do livro: consistiam em roteiros de leitura e estudo do livro texto, um guia para indicar os principais pontos e recomendar os exemplos de maior relevância para o entendimento dos conteúdos.

- vídeos sobre a matéria: consistiam em vídeos curtos do You Tube, uma vez que cada vídeo tinha, no máximo, 8 minutos de duração. Esses vídeos foram gravados e disponibilizados de forma livre por um professor externo a instituição e utilizados no AVA da disciplina sob a forma de curadoria digital, isto é, preservando os créditos do professor autor dos vídeos.

\subsection{Principais atividades propostas}

As atividades desenvolvidas tinham como objetivos, além da sua intencionalidade pedagógica intrínseca de auxílio na promoção do aprendizado, fazerem parte dos processos de avaliação e registro de frequência da disciplina. Os tipos mais utilizados de atividades foram os quizzes e fóruns.

$\mathrm{Na}$ maioria das vezes, a intencionalidade pedagógica dos quizzes era verificar de forma objetiva o entendimento de um conteúdo específico. Assim, por exemplo, logo após um vídeo, o quiz teria perguntas sobre os conteúdos recém estudados nesse vídeo. $\mathrm{Na}$ Figura 3, podemos visualizar um exemplo de pergunta frequente nos quizzes, enfatizando que a resposta teria como base o vídeo recém assistido. 
Figura 4 - Exemplo de atividade

\begin{tabular}{|c|c|c|c|}
\hline F & $\begin{array}{l}\text { 2020/1 - } 15000391 \text { - M51 - } \\
\text { CÁLCULO NUMÉRICOE }\end{array}$ & Questão & Uma expressão para $e^{x}$ é dada por \\
\hline 8 & $\begin{array}{l}\text { APLICAÇÕES } \\
\text { Participantes }\end{array}$ & $\begin{array}{l}\text { Ainda não } \\
\text { respondida }\end{array}$ & $e^{x}=1+x+\frac{1}{2 !} x^{2}+\frac{1}{3 !} x^{3}+\ldots=\sum_{n=0}^{\infty} \frac{1}{n !} x^{n}$ \\
\hline ¿ & Competências & $\begin{array}{l}\text { Vale } 50 \text { ponto(s). } \\
\text { 『 Marcar } \\
\text { questão }\end{array}$ & $\begin{array}{l}\text { Uma calculadora usa a expressão } \\
\qquad e^{x}=1+x+\frac{1}{2 !} x^{2}+\frac{1}{3 !} x^{3}\end{array}$ \\
\hline w & IVOTds & questão & para calcular as aproximações para $e^{x}$. \\
\hline$\square$ & Bem-vindos! & & $\begin{array}{l}\text { Com base no vídeo que você acabou de assistir, este tipo de erro } \\
\text { é classificado como: }\end{array}$ \\
\hline 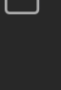 & $\begin{array}{l}\text { Informaçoes Essencials e } \\
\text { de Apoio }\end{array}$ & & Escolha uma ou mais: \\
\hline ك & Semana 01 - Fontes e & & $\square$ Erro de arredondamento. \\
\hline & Tipos de Erros & & $\square$ Erro de precisão dos dados. \\
\hline$\square$ & Semana 02 - Zeros de & & $\square$ Erro de truncamento. \\
\hline
\end{tabular}

Fonte: tela do AVA da disciplina de Cálculo Numérico e Aplicações - Semestre Alternativo 2020.

Os fóruns de discussões utilizados tinham intencionalidades pedagógicas diferentes:

- no fórum de exercícios semanais os estudantes tinham que postar soluções para alguns problemas propostos, devendo desenvolver uma resposta mais elaborada, com indicação clara dos métodos utilizados e cálculos realizados. Os fóruns de exercícios faziam parte do processo de avaliação. Nesses fóruns, os estudantes recebiam feedbacks ao passo que postavam suas resoluções, podendo, desde que dentro do prazo, fazer novas postagens nos fóruns.

- nos fóruns de dúvidas as postagens poderiam ter diversas motivações, desde dúvidas sobre o andamento da disciplina quanto dúvidas sobre os conteúdos estudados propriamente ditos. Esses fóruns não eram avaliados e, mesmo assim, os alunos podiam compartilhar dúvidas e respostas com os colegas e o professor.

$\mathrm{Na}$ Figura 5, temos um print de tela de um tópico do fórum de exercício da Semana 01 da disciplina. Para postar sua solução, cada aluno deveria acessar uma planilha do Google Sheets e seguir as instruções para gerar e fazer upload de um arquivo .PDF com a solução do exercício indicado.

Figura 5 - Fórum de exercícios

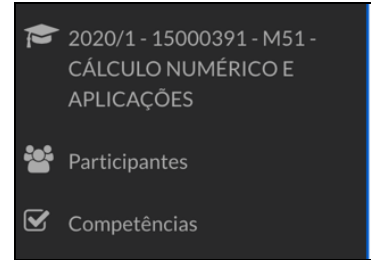

Exemplo - Exercício 1.2-2

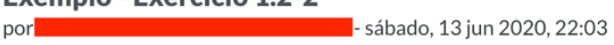

Exemplo

Resolução do Exercício 1.2-2. Siga as instruções do fórum para acessar a planilha do GoogleDocs e gerar o arquivo .PDF com a sua resolução.

Fonte: tela do AVA da disciplina de Cálculo Numérico e

Aplicações - Semestre Alternativo 2020. 


\subsection{Recursos externos (Google Sheet, Goglee Meet)}

Para além das ferramentas disponibilizadas dentro da plataforma Moodle no servidor e-AULA, decidimos utilizar duas ferramentas externas, fornecidas de forma gratuita pelo Google: as planilhas do Google Sheets e as salas virtuais do Google Meet.

A utilização das planilhas eletrônicas do Google Sheets se mostrou muito efetiva, pois permitia professor e alunos trabalharem de forma colaborativa e em tempo real, sendo possível, por exemplo, intervenções, por parte do professor, na parte de inserção de fórmulas e realização dos cálculos numéricos propriamente ditos. Todas as atividades avaliativas dos fóruns semanais ficaram organizadas em um único arquivo em que somente o professor e cada aluno, individualmente, tinham acesso.

No Google Meet foi criada uma sala de videoconferência permanente, com acesso restrito somente aos alunos, professor e monitor da disciplina. Nessa sala virtual eram realizados os atendimentos extraclasse pelo professor e onde os estudantes podiam encontrar o monitor para resolverem exercícios ou para esclarecimento de dúvidas. A opção de utilizar uma sala do Google Meet teve como principais motivadores: (1) fornecer uma alternativa ao servidor de webconferências da UFPel, uma vez que poderia ser utilizado mesmo quando o sistema institucional estivesse instável ou fora do ar; e (2) não sobrecarregar o servidor de webconferências da UFPel.

Para concluir essa seção sobre a organização e estrutura da disciplina de Cálculo Numérico e Aplicações, ainda podemos destacar a importância da diversificação dos recursos e atividades utilizados no AVA. Uma vez que indivíduos são diferentes, os processos de ensino-aprendizagem também ocorrem de forma diferente de um indivíduo para outro. Assim é fundamental o uso de diferentes tipos de ferramentas, umas complementares às outras, para promover o ensino-aprendizagem de forma mais efetiva. Além disso, a diversificação das ferramentas permite manter os alunos engajados e motivados. Na Figura 06, um exemplo de organização e estrutura semanal da disciplina.

Figura 6 - Semana 01 - Fontes e tipos de Erros

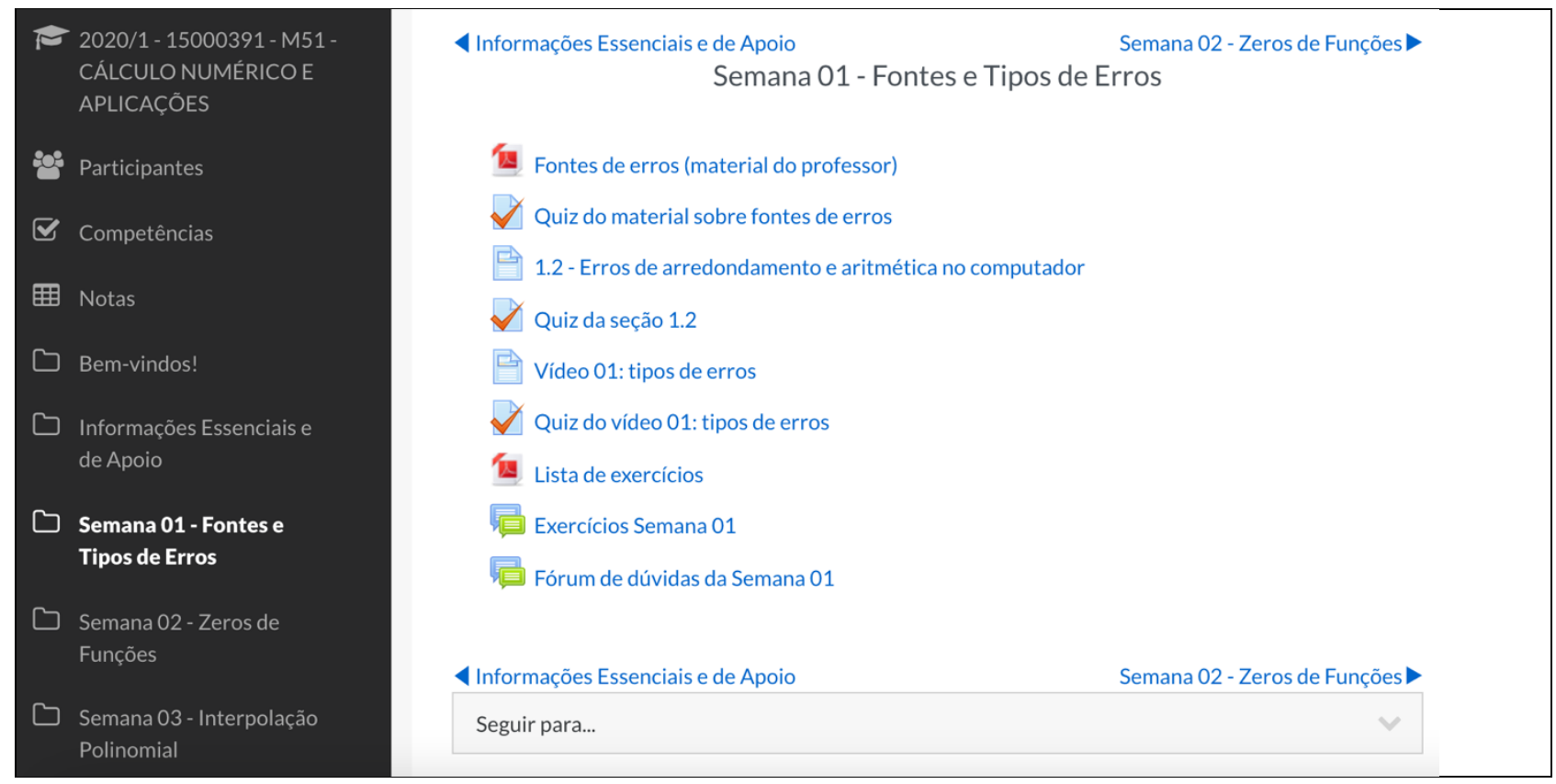

Fonte: tela do AVA da disciplina de Cálculo Numérico e Aplicações - Semestre Alternativo 2020. 


\section{PERFIL DOS ESTUDANTES}

O público-alvo das turmas de Cálculo Numérico e Aplicações é formado por estudantes a partir do quarto semestre dos diversos cursos de Engenharia do CEng. Como essa disciplina encerra o ciclo básico de disciplinas de Matemática e não é pré-requisito para disciplinas específicas ou profissionalizantes, alguns estudantes deixam a disciplina para seu último semestre de curso. Nesse contexto, e para que prováveis formandos pudessem cursar Cálculo Numérico e Aplicações, foi ofertada uma turma com 10 vagas no CA da UFPel. O número de vagas foi determinado levando em consideração todo o trabalho de planejamento, desenvolvimento e implementação da disciplina no formato de ERE e para que os alunos pudessem contar com um suporte adequado durante toda a disciplina, tanto para o aprendizado dos conteúdos específicos de cálculo numérico quanto para a utilização do AVA.

Para subsidiar as ações de planejamento, desenvolvimento e implementação da disciplina, foi realizada uma pequena pesquisa com os alunos da disciplina. Era importante conhecer um pouco das realidades e experiências de cada estudante no contexto do início da pandemia e retorno das aulas no formato de ERE. A maneira que os alunos iriam acessar a internet e os materiais disponíveis no AVA, provavelmente, teriam um impacto na relação de ensino-aprendizagem experimentada por cada um, assim como a experiência que cada aluno tem com a tecnologia também. Além disso, era importante conhecer um pouco das expectativas de cada estudante com relação a disciplina. O formato de ERE era novo e a maioria dos alunos não tinha experiência com estudos nessa modalidade ou em outra similar. Nesse sentido, a importância de conhecer as expectativas de cada um para que se pudesse esclarecer qual a proposta do trabalho adotada, além de discutir e adaptar as expectativas de todos de forma coletiva e compartilhada.

\subsection{Coleta de dados da pesquisa}

A pesquisa foi realizada através de um formulário eletrônico do Google Forms de forma a coletar as respostas de forma anônima, sendo facultada a identificação. A pesquisa foi divulgada por e-mail e através do fórum de avisos da disciplina no AVA e ficou disponível para receber respostas nas duas primeiras semanas de realização da disciplina. No total, 7 de 10 alunos responderam as perguntas de múltipla escolha e de resposta aberta.

\subsection{Resultados e análises}

Sobre a forma como os estudantes iriam acessar a internet, tipo e qualidade da internet, tipo de dispositivo utilizado e sistema operacional utilizado, nível de conforto com a tecnologia e algumas ferramentas, bem como sobre a experiência com a plataforma Moodle, perguntamos e obtivemos os seguintes resultados:

- Que tipo de internet você usa? Marque todas os tipos que você acessa com frequência.

- Você considera seu acesso a internet bom ou muito bom?

- Com que tipo de dispositivo você acessa a internet em geral? Marque todos os dispositivos que você utiliza com frequência.

- Qual o sistema operacional dos dispositivos que você usa com frequência? Marque todas as opções que se aplicam.

- Seu nível de conforto com tecnologia, em geral, é?

- Quais recursos de internet você usa com frequência, seja via navegador ou aplicativo. Marque todos que se aplicam.

- Marque o seu nível de familiaridade com cada um dos recursos Google gratuitos. Considere que 1 representa nenhuma e 5 muita familiaridade com o 
recurso. Para o Google Sheets, muita familiaridade significa utilizar/editar fórmulas e arrastar.

- Seu nível de familiaridade com o Moodle é?

Os estudantes relataram ter acesso a internet via rádio, móvel, via cabo e por fibra ótica. Nenhum estudante disse ter acesso via linha digital (ADSL) ou por satélite. Além disso, $78 \%$ dos alunos disseram ter um acesso muito bom a internet enquanto $22 \%$ disse que seu acesso era somente bom.

Sobre o tipo de dispositivo utilizado para acessar a internet, todos afirmaram ter acesso via um smartphone, alguns ainda disseram acessar a internet usando um notebook ou laptop e outros utilizando um computador de mesa, conforme a Figura 7. Os tipos de sistema operacional citados na pesquisa foram o Apple OS com 28,6\% e o Windows com $71,4 \%$, para os computadores pessoais.

Figura 7 - Tipo de dispositivos utilizados para acessar a internet com frequência

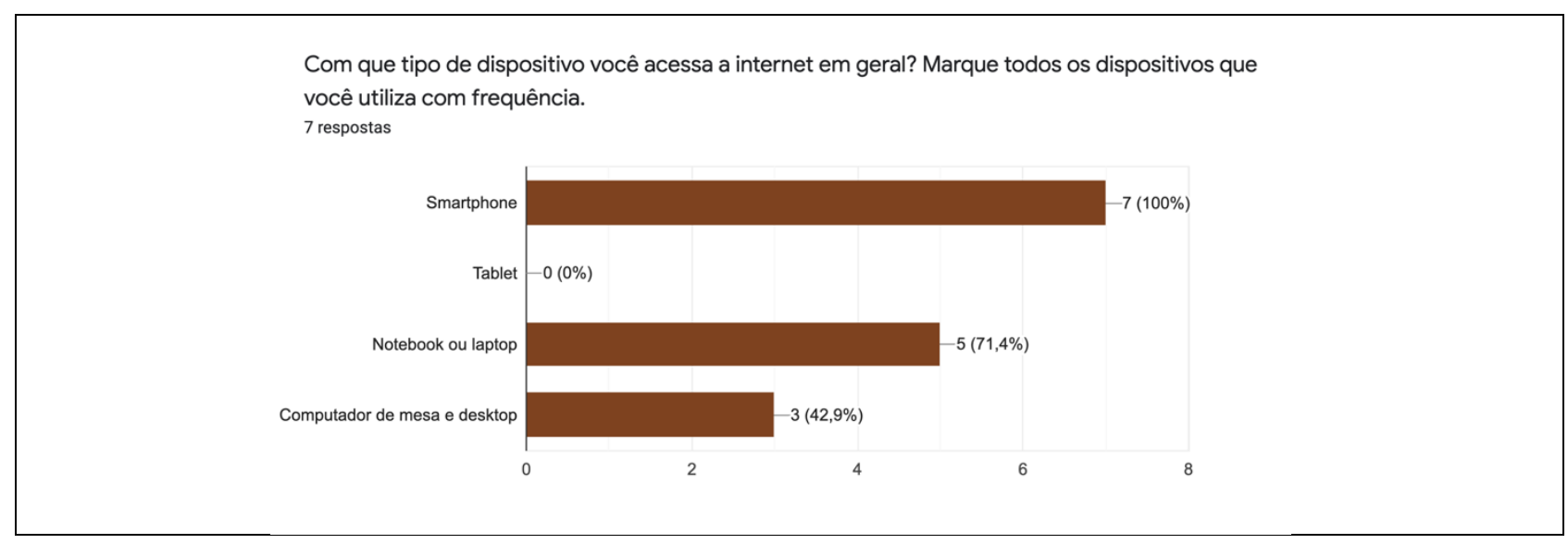

Fonte: pesquisa conduzida junto a disciplina.

Sobre o nível de conforto com a tecnologia, toda a turma afirmou se sentir, no mínimo, confortável com o uso da tecnologia. Nenhum aluno disse se sentir mais ou menos ou até mesmo não confortável com a tecnologia. A distribuição das respostas dadas pode ser visualizada na Figura 8.

Figura 8 - Nível de conforto com a tecnologia

Seu nivel de conforto com tecnologia, em geral, é 7 respostas
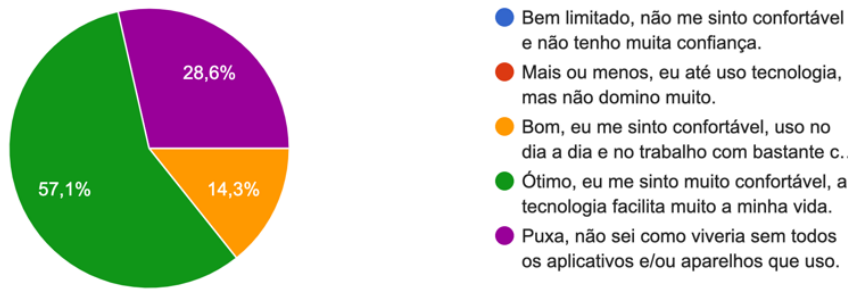

Fonte: pesquisa conduzida junto a disciplina. 
Quanto a alguns recursos utilizados com frequência na internet, foi possível observar que todos os alunos utilizam e-mail e WhatsApp, ver Figura 9. Tal fato, inclusive, motivou a adoção de um grupo de WhatsApp para comunicação rápida e objetiva de avisos e informações importantes da disciplina. Contudo, tal grupo não seria utilizado para tirar dúvidas referentes aos conteúdos da disciplina, sendo indicado, nesses casos, a utilização dos fóruns de dúvidas dentro do AVA.

Figura 9 - Recursos utilizados com frequência

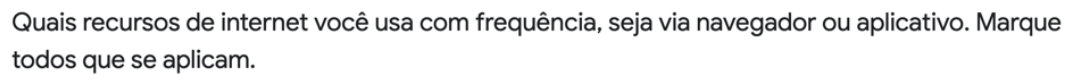
todos que se aplicam.

7 respostas

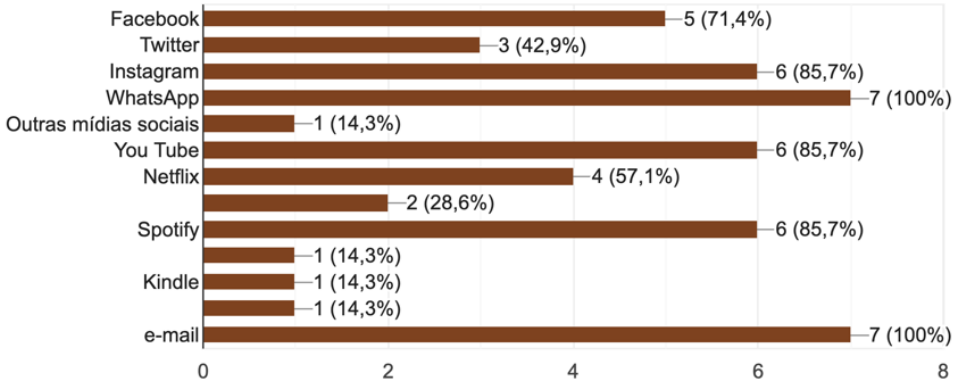

Fonte: pesquisa conduzida junto a disciplina de Cálculo Numérico e Aplicações.

Quanto ao nível de familiaridade dos estudantes com relação a alguns recursos gratuitos do Google, incluindo as planilhas eletrônicas do Google Sheets e sala de videoconferência do Google Meets, 1 estudante afirmou não conhecer o Google Meet e 2 estudantes não conhecerem o Google Sheets.

Finalmente, quanto ao nível de familiaridade com a plataforma Moodle, ver Figura 10, todos os estudantes afirmaram já terem alguma familiaridade, seja porque tiveram algum professor que utilizava o Moodle para acessar conteúdos e materiais didáticos, como um repositório, ou porque tiveram algum professor que utilizava o AVA não somente como repositório, mas, inclusive, para realizar atividades de avaliação.

Figura 10 - Nível de familiaridade com o Moodle

Seu nivel de familiaridade com o Moodle é 7 respostas
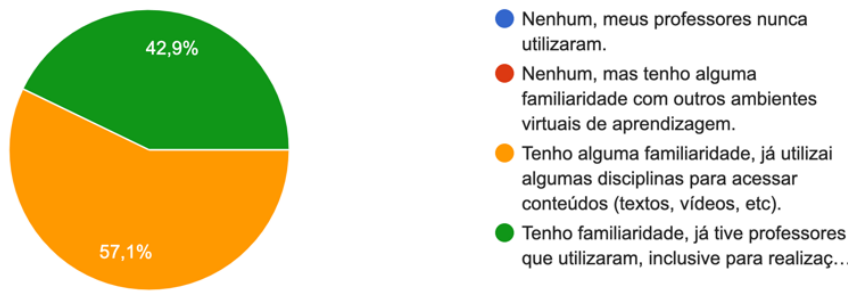

Fonte: pesquisa conduzida junto a disciplina. 


\section{CONSIDERAÇÕES FINAIS}

Ao planejar, desenvolver e implementar a disciplina de Cálculo Numérico e Aplicações sob a perspectiva do ERE, um dos objetivos era que a disciplina fosse conduzida de forma que os estudantes estivessem engajados a uma nova metodologia de ensino e novas possibilidades advindas do ERE. Nesta perspectiva do ERE, diferente das aulas das aulas presenciais, cuja metodologia baseia-se, frequentemente, na utilização de aulas expositivo-dialogadas, agora a base da disciplina é focada, principalmente, nos conceitos de uma aprendizagem autônoma, orientada e mediada por tecnologia.

Por aprendizagem autônoma queremos dizer que o estudante passa a desempenhar um papel mais ativo no processo de ensino-aprendizagem, o estudante é responsável pelo seu aprendizado, dependendo menos do professor para construir seus conhecimentos. Tal aspecto foi incentivado na disciplina quando propomos que os estudantes pudessem, de forma independente, (1) organizar suas agendas de estudo, uma vez que não havia atividades síncronas obrigatória, ou ainda (2) explorar diferentes materiais didáticos na internet, tendo, inclusive, a possibilidade de compartilhar tais materiais com os colegas da disciplina em espaço dedicado no AVA para tal, por exemplo.

Por aprendizagem orientada queremos dizer que o professor continua com o seu trabalho de orientação, guiando os estudantes através dos conteúdos estudados, dando destaque a pontos importantes da matéria e esclarecendo dúvidas. Neste sentido, as webconferências semanais e atendimentos extraclasses eram de vital importância, mesmo que com uma essência diferente das aulas presenciais.

Finalmente, por aprendizagem mediada por tecnologia queremos dizer que as tecnologias passam a fazer parte integrante e fundamental nos processos de ensinoaprendizagem. As próprias atividades realizadas no AVA como, por exemplo, quizzes e fóruns de discussões promoviam e convidavam a reflexão e entendimento dos conceitos estudados; da mesma forma que promoviam a interação entre alunos e desses com o professor. Também podemos destacar que enquanto nos quizzes a correção automática possibilitava ao aluno ter um feedback instantâneo ao testar seu aprendizado, nos fóruns de discussões havia a possibilidade de uma discussão e análise mais detalhada conteúdos ou métodos estudados.

Acreditamos que a pandemia de COVID-19 irá passar e esse formato de ERE será, de certa forma, abandonado, dando, novamente, espaço para as aulas presenciais, mas não para aulas presenciais clássicas. Vários aspectos explorados durante esse período de ERE poderão ser, mais uma vez, adaptados e incorporados ao que será um novo ensino presencial. Neste sentido, podemos nos perguntar: que tipo de mudança nos processos de ensino-aprendizagem vieram para ficar? Acreditamos que a utilização de AVA combinados com aulas presenciais poderão potencializar ainda mais a utilização de diversas ferramentas de forma a cada vez mais consolidar um modelo de aprendizagem autônoma, orientada e mediada por tecnologia.

\section{REFERÊNCIAS}

BREDARIOLI, Cláudia Maria Moraes. Do Ensino Remoto Emergencial à Educação Digital em Rede por Meio de Metodologias Ativas na Pandemia. In: $43^{\circ}$ Congresso Brasileiro de Ciências da Comunicação, 2020, Virtual. Anais. Virtual. Disponível em: http://www.intercom.org.br/sis/eventos/2020/resumos/R15-2490-1.pdf. Acesso em 23 abr. 2021. 
HODGES, Charles et al. The difference between emergency remote teaching and online learning. Educause review, v. 27, p. 1-12, 2020.

MOODLE. Documentação do Moodle em português. Disponível em: https://docs.moodle.org/all/pt br/. Acesso em 23 abr. 2021.

OLIVEIRA, Wanderson Kleber de et al. Como o Brasil pode deter a COVID19. Epidemiologia e Serviços de Saúde, v. 29, p. e2020044, 2020.

RONDINI, Carina Alexandra et al. Pandemia do Covid-19 e o ensino remoto emergencial: Mudanças na práxis docente. Interfaces Científicas-Educação, v. 10, n. 1, p. 41-57, 2020.

SOHRABI, Catrin et al. World Health Organization declares global emergency: A review of the 2019 novel coronavirus (COVID-19). International journal of surgery, v. 76, p. 71-76, 2020.

UNIVERSIDADE FEDERAL DE PELOTAS (UFPel). Portaria $\mathbf{N}^{\circ}$ 584, de 13 de março de 2020. Pelotas, 2020a.

UNIVERSIDADE FEDERAL DE PELOTAS (UFPel). Portaria $\mathbf{N}^{\circ}$ 585, de 13 de março de 2020. Pelotas, 2020b.

UNIVERSIDADE FEDERAL DE PELOTAS (UFPel). Portaria № 993, de 25 de maio de 2020. Pelotas, 2020c.

UNIVERSIDADE FEDERAL DE PELOTAS (UFPel). Parecer normativo $\mathbf{N}^{\mathbf{1}} \mathbf{1 2}$, de 28 de maio de 2020. Pelotas, 2020d.

\title{
EXPERIENCES ON NUMERICAL CALCULUS AND APPLICATIONS ON EMERGENCY REMOTE TEACHING AT UFPEL
}

\begin{abstract}
In this work, we report on how the discipline of Numerical Calculus and Applications was organized and structured for a small class of students at the Center of Engineering of the Federal University of Pelotas in the context of the COVID-19 pandemic. Such class was taught in an emergency remote teaching perspective in the year 2020. We present the main explored tools within the virtual learning environment and how they were used in the teaching-and-learning processes, assessment and attendance records. In addition, we present the results and some analyzes of a survey conducted with students enrolled in this class in order to know the profile of these students and, thus, be able to anticipate difficulties and/or explore the potential of emergency remote teaching.
\end{abstract}

Keywords: numerical calculus, emergency remote teaching, virtual learning environment. 